\title{
Discussion on Longevity Thoughts of Taiping Jing
}

\author{
Yongfeng Huang \\ Department of Philosophy \\ Xiamen University \\ Xiamen, China
}

\begin{abstract}
Taiping Jing" is one of the classics of Taoism at early stage, containing a wealth of longevity thoughts, mainly including keeping "One" for longevity, kindness and longevity, medicine nursing and refraining for health and other aspects. These ideas play a positive role in enlightening the Taoists and the public at that time and thereafter, which are worthy of our careful research.
\end{abstract}

Keywords-Taoism; Taiping Jing; longevity

\section{INTRODUCTION}

"Taiping Jing" was developed by many people gradually at the late Western Han Dynasty to Emperor Shun period of Eastern Han Dynasty. According to the historical records such as History of Later Han Dynasty, Yu Ji and Fong Chong are the important authors of this book. This book is the representative of Taoist classics at early stage with great influence. "Taiping Jing" considers that "Born is the First" between heaven and earth [1], which is a typical manifestation of the teachings of Taoism. In order to achieve the goal of longevity, many thoughts on this regard have been summarized in "Taiping Jing", which will be explained mainly from the following four aspects.

\section{KEEPING ONE FOR LONGEVITY}

Keeping one is Taoist practice alchemy, means keeping jing, qi, shen, dantian or other parts of the human body in unification between spirit and body, to achieve a long life. "Taiping Jing" thinks "one" has the attributes of the roots, which is ideological basis to keep one-keeping alchemy. In the "Taiping Jing", it is said, "one (unification) is the foundation of a way and also the headspring of vigor, and also the primary of public mind." [2] "One, is the beginning of quantity, the way of life, the headspring of vigor, the rule of the world .... and the origin of all things." [3] That means "One" is the foundation of a way, the headspring of vigor, the rule of the world, origin of all things, sustainer of life. Since "one" is so important, we must keep it to want a long life. "If people can keep 'one'", "we will be survivable" [4].

To keep "One", we shall know what "One" refers to first of all. There are explains in "Taiping Jing". The article of Method for Keeping One and Driving out Evils of "Taiping Jing" says that "the "One" of head is the top of the head; the "One" of seven organs (seven organs refer to ears, eyes, mouth, nose) is the eye; the "One" of belly is navel; the "One" of pulse is Qi; the "One" of five internal organs is heart; the "One" of for limbs is the center of hands and feet; the "One" of bone is spinal cord; the "One" of meat is intestines and stomach." [5]The article of Making People Longevity and Peace says that "Three Qi makes One... one is Jing, one is Shen and the other is Qi. These three form one level, which is originally the Qi of heaven, earth and human. Shen is derived from heaven, Jing is derived from earth, Qi is derived from Zhonghe, and they form one doctrine together." [6]Therefore, "those who want longevity shall keep Qi and integrate Shen and Jing without removing there forms, thus to integrate these three into one" [7]. It can be seen from the above that the "One" of keeping one can be a certain part of human body, and the unity of Jing, Qi and Shen. There is no clear definition, we just need to concentrate our minds and take "One" to keep.

The specific methods of keeping "One" have been explained in detail in "Taiping Jing". First is the preparation for keeping "One". A peace and quiet place shall be selected for keeping "One", eat less and remove dirty, as well as sit and lie on a flat bed. "Taiping Jing" says that: "keeping "One" starts thinking to live in a leisure place, and it is better a place with thick walls without hearing noises." "To keep "One", the essential factor is to eat less, keep intestines and stomach free from much too foods." "If one wants to live out one's life in retirement, it is better to keep "One" early, sit and lie on flat bed, guard each other with the "One", then he will be full without eating, thus to gain longevity." [8] Second, essentials to keep "One". "Close the door without leakage, keep God in his mind sincerely, with dark exterior and bright interior. Then the "One" can be formed." [9]This is to say that while keeping "One", one shall close his ears, eyes, mouth, nose and tongue cautiously to concentrate his mind. To keep "One", one shall not be puzzled by the emotions of joy and anger. "Joy and anger are the diseases for keeping "One", and the "One" can be obtained if one lives without joy or anger" [10].Keeping "One" shall be made gradually and naturally. "Keeping "One" starts gradually, and one can keep longer if he insists on it." "As for keeping "One", one-hundred day is small quite, twohundred day is milled quite, and three-hundred day is large quite." "For keeping "One", there is no shortcut, and the effect can be obtained if one can keep it." "The method for keeping "One" varies among the old and the young. One can obtain the "One" if he keeps it based on his own characteristics." [11] To keep "One", one shall also remove honor and power, and do good things.

"Taiping Jing" thinks that keeping one has very large health function, "keeping one makes people vigorous, hair black and new teeth fast come out. Keep one for one day, life increases one year; for two days, two years, and for more days, 
more years." [12] Moreover, keep one will achieve success of all things. "If keeping one, a man can be secular and free from disaster, can conduct himself in society, free from death, and can manage well family affairs, keep heavenly-minded, free from privation and illness, and be immortal. Keeping one is the orgin of vigour and the key of all things."[13]. Therefore, "Taiping Jing" proposes that, "in any way, one-keepting alchemy is always followed. [14]

\section{DoING GoOd DeEDS CAN LIVE A Long LiFE}

"Taiping Jing" closely connects immortality faith and ethical culture and emphasizes one can live a long life if he does good deeds and die young if he does evil. Since we can live a long life if we do good deeds, what is good? How to do good deeds? The piece of "Taiping Jing", "Commandments on Great Merit and Longevity", says, "filial piety, loyalty, sincerity and integrity are the most important things in the world, so we shall be not proud and undisciplined, or we cannot live a long life." [15] It means that deities will deprive our life if we do evil, so that people shall "know about good and do the good, know about integrity and be honest, know about loyalty and be loyal to others, know about obedience and be obedient, and know about filial piety and be filial" [16]. It shows that good mentioned in "Taiping Jing" is traditional standard of human relations according to feudal ethics in China. The early Taoism thinks that people will live a long life with good eyes and ears if they propagate and uphold traditional Chinese moral principles. For this possibility, "Taiping Jing" has the following three arguments that connect with each other closely.

Firstly, provide vivid examples that people will live a long life if they do good deeds and will die if they do evil. The piece of "Longevity Commandment" of "Taiping Jing" depicts the story that the posthumous child of an evil person is alone and helpless, becomes flunkey and calls back the spirit of his dead father, receives pity from gods and treats life with the proper methods and admonishes his children to do good deeds. It vividly and clearly shows: do good deeds all the time, do not behave unscrupulously, do not take away the money of others, do not drink at random, and do not believe right and wrong easily. It thinks that if one can do this, he will live a long life. Similar cases are clearly described in sections and chapters of "Commandment on Filial Piety and Longevity" and "Knack on Establishment of Ancestral Hall”.

Secondly, deities supervise, reward the virtuous and punish the wicked. Authority of deities supports that prove people will live a long life if they do good deeds and will die young if they do evil. "Taiping Jing" thinks there are many deities in the world even in human body. They are dispatched by the god, observe good and evil of people and take charge of people's life. "Deities will know good and evil of people", [17], "reward people who do good deeds and punish people who do evil" [18]. Deities have an insight into good and evil of people and tell it to the god. The god rewards and punishes them according to their behaviors. People will live a long life if they do good deeds. If people have great merit, they can prolong life and bless descendants; people who do good deeds are blessed by deities. They can live a long life and become immortal. "Taiping Jing" depends on authority of deities to connect good and evil of people with their life and death, exhorts people to do good deeds instead of doing evil, to live a long life and become immortal.

Thirdly, put forward the theory of bearing to explain the phenomenon that people die young when they do good deeds and people live a long life when they do evil. The statement in "Taiping Jing" that people will live a long life if they do good deeds has great rallying point for general believers, but it often faces embarrassment: In real life, some people die young when they do good deeds, but some people prolong life joyfully when they do evil. In order to explain this paradox, "Taiping Jing" puts forward, "if one suffers pain when he does good deeds, he bears the fault of his forefathers. Adversities accumulate and do harm to this person; if one enjoys life when he does evil, he was blessed by great merits accumulated by his forefathers" [19]. This statement of "Taiping Jing" explains the opinion of retribution for good and evil of Taoism. It is one of the theoretical cornerstones of Taoism.

After "Taiping Jing" carefully discusses and analyzes the opinion that doing good deeds can bring long life, it calls upon common people, "strive to do good deeds and do not do evil, so that they will live a long life. If people do not want to do good deeds, they shorten life expectancy by themselves. If people want to die instead of living a long life, even the god cannot help them". [20] "Taiping Jing" also advocates, "It is better to practice what one preaches than say good words" [21], thinks that behavior is more important than language and exhorts people to pursue longevity with practical practice.

\section{MEDICINE REGIMEN}

The medicine regimen idea of "Taiping Jing" mainly includes vegetation prescription, biology prescription and acupuncture. Vegetation prescription refers to vegetable drugs and prescription. Biology prescription refers to animal drugs and prescription. In "Taiping Jing", two articles of "Vegetation Prescription Knack" [22] and "Biology Prescription Knack" [23] intensively touch upon vegetation and biology prescription. The two articles clearly embody characteristics of early Taoism regimen. Firstly, in terms of source of drugs and prescriptions, "Taiping Jing" thinks that vegetation prescription and biology prescription come from the heaven, "grass used as a medicinal herb from the heaven can treat disease immediately and grow on the ground; plants used as medicinal herb from the heaven can prolong life of people immediately and grow on the ground", "almighty medicine from the heaven exists in the body of animals. The god makes them become prescription". The thought in "Taiping Jing" that medicines come from the heaven shows that the cognition of author has obvious religious theology color. Secondly, in terms of prescription classification, "Taiping Jing" has considerable thoughts of drug classification. According the speed of cure, plant medicine can be divided into: prescription for cure in a day, prescription for cure in two days, prescription for cure in three days, prescription for people to wait for death; according to curative effect, plant medicine can be divided into: Diwang herb medicine, Dachen herb medicine, Renmin herb medicine and herb medicine that delays the treatment, and biology prescription can be divided into: tianshen prescription (or called Diwang Shanghuang miraculous prescription) and 
Dijing prescription (miraculous prescription of Wuhou). Drug classification of "Taiping Jing" takes on religious and political color, but reflects active absorption of Taoist followers for medical practice results at that time as well. Thirdly, in terms of pesticide effect, "Taiping Jing", on one hand, thinks the magical curative effect of drugs is that "it can be used by heaven, earth, people, soul and ghost"; on the other hand, also puts forward the reason why drug takes effect is that it has "Jing". Popular idea in Han dynasty thinks that "Jing" is a subtle material. "Grass and trees have spirit", "Biology walk with spirit". It tends to materialism. The two opposing views exist in "Taiping Jing" simultaneously. They are seemingly contradictory, but in reality, it is true reflection of ideological level of Taoist priest at that time and reflects limitation of the era. Fourthly, in terms of medical ethics, "Taiping Jing" has simple people-centered idea. With only hundreds of words, two short articles of "Vegetation Prescription Knack" and "Biology Prescription Knack" mention physicians need to be careful in using drugs for three times. The idea of "Taiping Jing" in caring for life embodies the spirit of Taoism in "valuing life" and "cherishing life". Lastly, the end of "Biology Prescription Knack" warns people: natural law abhors slaughter. Animals have feelings. We shall not kill animals easily and use it as medicine. If we are badly in need of them indeed, we shall wait for them to become mature. The idea that forbids killing young animals to protect animals is valuable.

The "Acupuncture Knack" [24] in "Taiping Jing" mainly discusses acupuncture moxibustion therapy. The article states composition, operation and abnormal performance of main and collateral channels of people and then discusses the effect of acupuncture, principle and method of hand-manipulating of needles as well as clinical consultation. The length of "Acupuncture Knack" is not long, but the contents discussed in it are key points of acupuncture moxibustion therapy. The beginning of "Acupuncture Knack" discusses theoretical basis of acupuncture, "moxibustion and acupuncture can nurse three hundred and sixty channels, regulate Qi of Yin and Yang and treat disease. The three hundred and sixty channels correspond to three hundred and sixty days of a year. Each channel beats in every day according to four seasons and five elements", "moxibustion refers to Jing of Taiyang ... Silver needles refer to Jing of Shaoyin". These statements follow traditional view of doctor of traditional Chinese medicine that pulse position has relationship with yin-yang and five elements and run through idea of yin-yang and five elements. In the so-called "Jing of Taiyang", Taiyang is one of the epidemic infectious diseases, corresponding to summer in the south and presents fire in the five elements. Because moxibustion means using burning moxa to smudge certain acupuncture points and relates to fire, moxibustion is "Jing of Taiyang". Similarly, in "Jing of Shaoyin", Shaoyin is one of the epidemic infectious diseases, corresponding to autumn in the west and presents metal in the five elements. Because silver needles are made by metal, it is called "Jing of Shaoyin". Acupuncture method naturally connects acupuncture and moxibustion with theory of yin-yang and five elements. Similar to "Vegetation Knack" and "Biology Knack", "Acupuncture Knack" embodies the idea of Taoism in valuing life. "Vegetation Knack" and "Biology Knack" advocate that physicians shall be double cautious in using drugs. "Acupuncture Knack" suggests clinical consultation and thinks only in this way can people give play to magical curative effect of acupuncture. "Acupuncture Knack" also proposes implementing treatment through distinguishing symptom and thinks the figure of people is different, so it is necessary to capture acupuncture points in accordance with each individual. However, "Acupuncture Knack" is also partial to some extent. It touches upon "yang channels should have been adjusted, but the physician treats yin channels, which hurt people and shorten their life", and does not conform to the idea of traditional acupuncture in traditional Chinese medicine. "The Piece of Basic Concepts and Laws of Yin and Yang" in "Huangdi Neijing Plain Questions" specially discusses this problem and puts forward, "People who is good at using silver needles can induce yang from yin, induce yin from yang, puncture the right to treat the left and puncture the left to treat the right, know that side according to this side and know the interior from the exterior." On the whole, although there are some defects in "Acupuncture Knack", it can yet be regarded as an excellent work that discusses technique of longevity through acupuncture.

\section{REFRAINING FOR HEALTH}

"Taiping Jing" thinks that refraining is also a way for longevity, "those who eat food have a life with term, those who don't eat are like the God, those who eat vitality have deity, and those who drink and eat will have a long life equal to heaven and earth." [25]. These tell us in brief that: people who eat grain have a limited life term, people who are good at regulating Qi are deities and understand all things, and people who do not drink or eat something tangible survive with heaven and earth. Here, eating or drinking nothing is refraining, namely not to eat the whole grains, but not eat or drink nothing. In fact, the Refraining Method advocated by "Taiping Jing" and Taoism thereafter, often accompanied eating Qi and medicine.

Refraining is effective, but the method shall be correct. "If one wants to refrain his food, he shall put prescription guiding life before him for remaining Qi. Within three days after the Qi medicine is taken, he will feel a little hungry, within seven days, there will be a micro hungry, more than 10 days later, he may feel small achievements without confusion, and he can get away from death for longevity." [26] That is to say, before refraining, some medicines with the effects of nourishing shall be taken first of all. After the Qi medicine is taken, he may feel a little hungry within three days, a little more hungry within seven days, and more than ten days later, he will be adapted to it preliminarily without confusion, and at that time, he may get away from death for longevity. It has been mentioned above, refraining is not eating nothing, but to diet slowly, and eat less; not eat the usual food, some "special" food are needed. "After the Qi medicine is taken, those who eat tangible food and have difficulty in digesting it, the food shall be changed once a day, and those whole eat intangible objects, it is better to eat less... Eating less is good, eating more is bad, and eating nothing is bad, too, as it can make intestines and stomach block up." [27] This passage repeatedly states that in refraining process, the appetite shall be controlled, and it is suitable to eat hard food 
once a day, and try best to eat less of the liquid food; but eat nothing will cause gastrointestinal barrier, affecting health. The so-called "objects that are tangible and difficult to be digested" means those thing that have high nutrition and can be digested slowly, such as pine nuts, platycladi seeds, fructus cannabis that contain rich vegetable oil, as well as liriope, rehmannia, Poria cocos, yam, Astragalus, ginseng and other rhizome or sclerotium containing a variety of sugars, starch, vitamins and other ingredients. The so-called "intangibles" refers to flax soup, crisp soup, wine or water and other liquid things. People who are refraining have relatively less movement, and these foods can meet their basic nutritional needs. In addition, the "Pacific Classic" also reminds them to "often make their belly in for convenient of walking" [28], that is to say, the waist belt shall often be fastened to walk.

"Taiping Jing" believes that the implementation of refraining can keep individual healthy, and can make all the beings healthy. As for individual, "it can remove disease, make him /her looks better, without defense and prevention. The anti-ancient old men who are enlightened all thanks to not eating." [29]. As for a country, "this is the method to make the country rich and people survive", it can "help countries to feed people, and assist the eating ones worldwide", "people at all levels can keep peace physically and mentally, to perform their own responsibilities; the rich one can save their money, the poor can survive; if a gentleman implement it, there will be good times, which will not die in bad years."[30]. Therefore, "Taiping Jing" advocates using our own method, and performing everything by ourselves, to gain benefits in good times, and enable people to survive in bad years" [32]. We can find from the refraining method advocated by "Taiping Jing" the pursuit of longevity and governing philosophy of Taoism at early stage.

We have discussed the longevity thoughts of "Taiping Jing" from four aspects of keeping "One" for longevity, kindness and longevity, medicine nursing and refraining for health. These ideas are profound and valuable. As for Taoism itself, "Taiping Jing" is the masterpiece for Taoism to administering individual and governing the country. Its longevity concept and operation types play a guiding role for the Taoists' physical and psychological practice. With respect to social impact, "Taiping Jing" has inherited the longevity culture prior to it, absorbed the longevity wisdom for the time being, and inspired the longevity pursuers thereafter. In this sense, "Taiping Jing" is an important part of Chinese health science. Today, the longevity principles as well as longevity objectives of keeping both ourselves and others healthy of "Taiping Jing" are still shining brightly.

\section{REFERENCES}

[1] Wang Ming: Collection of Taiping Jing, Beijing: Zhonghua Book Company, Version 1960, P.613.

[2] Wang Ming: Collection of Taiping Jing, Beijing: Zhonghua Book Company, Version 1960, P.12-13.

[3] Wang Ming: Collection of Taiping Jing, Beijing: Zhonghua Book Company, Version 1960, P. 60.

[4] Wang Ming: Collection of Taiping Jing, Beijing: Zhonghua Book Company, Version 1960, P. 716.
[5] Wang Ming: Collection of Taiping Jing, Beijing: Zhonghua Book Company, Version 1960, P.13.

[6] Wang Ming: Collection of Taiping Jing, Beijing: Zhonghua Book Company, Version 1960, P.728

[7] Wang Ming: Collection of Taiping Jing, Beijing: Zhonghua Book Company, Version 1960, P.716

[8] Wang Ming: Collection of Taiping Jing, Beijing: Zhonghua Book Company, Version 1960, P.740-742.

[9] Wang Ming: Collection of Taiping Jing, Beijing: Zhonghua Book Company, Version 1960, P.741.

[10] Wang Ming: Collection of Taiping Jing, Beijing: Zhonghua Book Company, Version 1960, P. 741.

[11] Wang Ming: Collection of Taiping Jing, Beijing: Zhonghua Book Company, Version 1960, P. 741-742.

[12] Wang Ming: Collection of Taiping Jing, Beijing: Zhonghua Book Company, Version 1960, P. 740,

[13] Wang Ming: Collection of Taiping Jing, Beijing: Zhonghua Book Company, Version 1960, P. 743.

[14] Wang Ming: Collection of Taiping Jing, Beijing: Zhonghua Book Company, Version 1960, P.16.

[15] Wang Ming: Collection of Taiping Jing, Beijing: Zhonghua Book Company, Version 1960, P. 543.

[16] Wang Ming: Collection of Taiping Jing, Beijing: Zhonghua Book Company, Version 1960, P. 540.

[17] Wang Ming: Collection of Taiping Jing, Beijing: Zhonghua Book Company, Version 1960, P. 12.

[18] Wang Ming: Collection of Taiping Jing, Beijing: Zhonghua Book Company, Version 1960, P. 527.

[19] Wang Ming: Collection of Taiping Jing, Beijing: Zhonghua Book Company, Version 1960, P. 22.

[20] Wang Ming: Collection of Taiping Jing, Beijing: Zhonghua Book Company, Version 1960, P. 621.

[21] Wang Ming: Collection of Taiping Jing, Beijing: Zhonghua Book Company, Version 1960, P. 25.

[22] Wang Ming: Collection of Taiping Jing, Beijing: Zhonghua Book Company, Version 1960, P. 172-173.

[23] Wang Ming: Collection of Taiping Jing, Beijing: Zhonghua Book Company, Version 1960, P. 173-174.

[24] Wang Ming: Collection of Taiping Jing, Beijing: Zhonghua Book Company, Version 1960, P. 179-181.

[25] Wang Ming: Collection of Taiping Jing, Beijing: Zhonghua Book Company, Version 1960, P. 700.

[26] Wang Ming: Collection of Taiping Jing, Beijing: Zhonghua Book Company, Version 1960, P. 684.

[27] Wang Ming: Collection of Taiping Jing, Beijing: Zhonghua Book Company, Version 1960, P. 684.

[28] Wang Ming: Collection of Taiping Jing, Beijing: Zhonghua Book Company, Version 1960, P. 685.

[29] Wang Ming: Collection of Taiping Jing, Beijing: Zhonghua Book Company, Version 1960, P. 684.

[30] Wang Ming: Collection of Taiping Jing, Beijing: Zhonghua Book Company, Version 1960, P. 684.

[31] Wang Ming: Collection of Taiping Jing, Beijing: Zhonghua Book Company, Version 1960, P. 684-685.

[32] Wang Ming: Collection of Taiping Jing, Beijing: Zhonghua Book Company, Version 1960, P. 685. 